\title{
Expression of Helicobacter Pylori TonB Protein in Transgenic Arabidopsis Thaliana: Toward Production of Vaccine Antigens in Plants
}

\author{
Irina Kalbina, ${ }^{,}{ }^{\dagger}$ Lars Engstrand, ${ }^{\ddagger}$ Sören Andersson, ${ }^{\star,}$, , \\ *Örebro Life Science Center, Örebro University, SE-70182 Örebro, `School of Science \& Technology, Örebro University, SE-70182 Örebro, \\ ${ }^{\ddagger}$ Department of Biotechnology, Swedish Institute for Infectious Disease Control (SMI), SE-17182 Solna, ${ }^{\S}$ Department of Clinical Microbiology, \\ Örebro University Hospital, SE-70185 Örebro, "Department of Virology, Swedish Institute for Infectious Disease Control (SMI), SE-17182 Solna, \\ Sweden
}

\section{Keywords}

edible vaccines, Helicobacter pylori, HP1341, subunit vaccine, TonB, transgenic plants.

Reprint requests to: Åke Strid, Örebro Life Science Center, School of Science \& Technology, Örebro University, SE-70182 Örebro, Sweden. E-mail: ake.strid@oru.se

\begin{abstract}
Background: The aim of this study was to produce a recombinant version of the highly antigenic Helicobacter pylori TonB (iron-dependent siderophore transporter protein HP1341) in transgenic plants as a candidate oral vaccine antigen.

Materials and Methods: Using Agrobacterium-mediated gene transfer, we introduced three different constructs of the ton $B$ gene into genome of the model plant Arabidopsis thaliana. We investigated transgene insertion by PCR, produced TonB antibodies for analysis of the production of the recombinant protein in plants, verified the identity of the protein produced by mass spectrometry analysis, and analyzed the number of genetic inserts in the plants by Southern blotting.

Results: Three different constructs of the expression cassette (full-length ton $B$, ton $B$ truncated in the $5^{\prime}$ end removing the codons for a transmembrane helix, and the latter construct with codons for the endoplasmic reticulum SEKDEL retention signal added to the $3^{\prime}$ end) were used to find the most effective way to express the TonB antigen. Production of TonB protein was detected in plants transformed each of the constructs, confirmed by both Western blotting and mass spectrometry analysis. No considerable differences in protein expression from the three different constructs were observed. The protein concentration in the plants was at least $0.05 \%$ of the total soluble proteins.

Conclusions: The Helicobacter pylori TonB protein can be produced in Arabidopsis thaliana plants in a form that is recognizable by rabbit anti-TonB antiserum. These TonB-expressing plants are highly suitable for animal studies of oral adminstration as a route for immunization against Helicobacter infections.
\end{abstract}

Helicobacter pylori colonizes the human stomach mucosa and is the main cause of peptic ulceration and gastric cancer [1,2]. Current antibiotic-based therapies, commonly including two antibiotics and a proton pump inhibitor, are not sufficient or feasible for global control of the infection because of their high cost, development of antibiotic resistance, and possible side effects of the antibiotics [3]. Today, a low treatment success is mainly related to a growing resistance problem in many geographic areas $[4,5]$. Consequently, development of an effective and relatively cheap vaccine against $H$. pylori is of great importance. Considerable efforts have been made during recent years to develop an effective vaccine against $H$. pylori although with limited success so far. Reasons for this might be the need for additional effective protective antigens or antigen formulations or the ineffectiveness of the present delivery routes. Furthermore, the interactions between the bacteria and the local immune system are complicated and not fully understood. An effective vaccine against $H$. pylori would 
probably have to induce an immune response at the major locations of the infection and preferably interfere with such important mechanisms as bacterial motility, penetration of and adherence to mucosal surfaces, enzyme activation, and toxin production [6].

A study made recently by Meinke et al. [7] revealed an antigenic profile of two $H$. pylori strains isolated from patients with gastric cancer and duodenal ulcer, respectively. The most promising antigen candidates were selected on the basis of gene conservation, recognition by antibodies, and in silico analysis. The iron-dependent siderophore transporter protein (TonB, HP1341) was shown to be the most immunogenic and may be a promising candidate as a vaccine antigen. To colonize and survive the acidic environment in the human stomach, H. pylori needs a constant supply of micronutrients including nickel and iron ions [8]. At low $\mathrm{pH}$, these ions are essential to maintain $\mathrm{pH}$ homeostasis and to support bacterial growth. The uptake of nutrients in H. pylori is performed by active transport over the cell membrane. Three different factors are required for the active transport of ions across the outer membrane in Gram-negative bacteria: a proton-motive force (pmf) that drives the transport over the membrane, a transmembrane complex composed of TonB, ExbB, and ExbD (the TonB complex), and a specific TonBdependent transporter (TBDT) in the outer membrane [9]. The TonB complex uses the proton gradient over the cytoplasmic membrane to induce conformational changes in TBDT. This will lead to release of vitamin $B_{12}$ that in turn initiates substrate transport over the outer membrane. TonB consists of one single transmembrane helix, a proline-rich linker region, and a periplasmic C-terminal sequence [10].

Although the main location of the $H$. pylori infection is in the mucosal tissues of stomach, it is important to expose a candidate vaccine antigen to the gut-associated lymphoid tissue (GALT) in the gastrointestinal tract [11]. Such exposure can be achieved by oral delivery of the vaccine [12-14], and transgenic edible plants are promising candidates as producers of this type of vaccine or even as vaccine carriers. Plant-produced vaccines are subunit vaccines and therefore are unable to replicate in the host. This makes them safer than attenuated vaccines based on the bacterium itself with no risk of pathogen transmission. Plant-based edible vaccines are safe, cheap (assuming that they are sufficiently immunogenic), and could be grown locally. In addition, transgenic plants are capable of producing several different antigens in the same individual for instance by crossing transgenic plant lines yielding the particular antigens of choice. Prototype edible plant vaccines against enterotoxigenic Escherichia coli (ETEC) [15,16], cholera [17,18], norovirus [19,20], and hepatitis B [21] have shown promising results in ani- 1 mals and in pilot studies in humans - transgenic plants can stimulate a two-way immune response, both systemically and mucosally.

The aim of this study was to create transgenic Arabidopsis thaliana plants producing recombinant TonB protein from $H$. pylori. We produced TonB protein in plants in its full-length form as well as in a truncated form (lacking its $\mathrm{N}$-terminal trans-membrane helix). To possibly enhance the expression level of the recombinant plant-produced TonB, we also added nucleotides for the endoplasmic reticulum retention signal SerGlu-Lys-Asp-Glu-Leu (SEKDEL) to the genetic construct [22,23]. Also, in the latter construct, we used a tandem of four $35 \mathrm{~S}$ enhancers from the cauliflower mosaic virus in the promoter controlling expression of the ton $B$ gene. Expression of TonB protein was detected in plants transformed with each of the three constructs using TonB-specific antibodies. No significant differences in protein expression between the different constructs were observed. The estimated protein concentration in plants was at least $0.05 \%$ of the total soluble proteins.

\section{Methods}

\section{Transgene Construction}

PCR amplification of the ton $B$ gene was performed from a vector constructed previously (ton $B$ in pET28C vector, Novagen, Inc., Madison, WI; Ref. 7). The PCR utilized Ex Taq DNA polymerase (Takara Bio Inc, Shiga, Japan) and consisted of 35 cycles of $98{ }^{\circ} \mathrm{C}$ (10 seconds), $65{ }^{\circ} \mathrm{C}$ (30 seconds), and $72{ }^{\circ} \mathrm{C}$ (2 minutes), followed by extension at $72{ }^{\circ} \mathrm{C}$ ( 15 minutes). The sequences of the primers used in the PCR are shown in Table 1. We designed three different constructs (Fig. 1): (A) the entire TonB (TonB) under control of $35 \mathrm{~S}$ promoter (primers A \& B); (B) the truncated TonB (tTonB) without the $\mathrm{N}$-terminal transmembrane helix under control

Table 1 Nucleotide sequences of primers used for PCR cloning of tonB. Restriction sites are denoted in bold, start and stop codons are denoted in italics, and the ER retention sequence is underlined

\begin{tabular}{|c|c|}
\hline Primer name & Sequence $\left(5^{\prime} \rightarrow 3^{\prime}\right)$ \\
\hline A & GATCTCTAGA ATG AAAATTTCTCСАTCTCC \\
\hline$B$ & CATCGGATCC TCA GTCTTCTTTCAAGCTA \\
\hline C & GTTTGTCTAGATTTTA ATG CGCGAAGACGCC \\
\hline D & GTTTGGATCCTTTTTA ATG CGCGAAGACGCC \\
\hline \multirow[t]{3}{*}{ E } & CATCGGATCC TCA TAG CTC ATC TTT CTC AGA \\
\hline & GTCTTCTTTCAAGCTA \\
\hline & L $\quad E \quad D$ \\
\hline
\end{tabular}




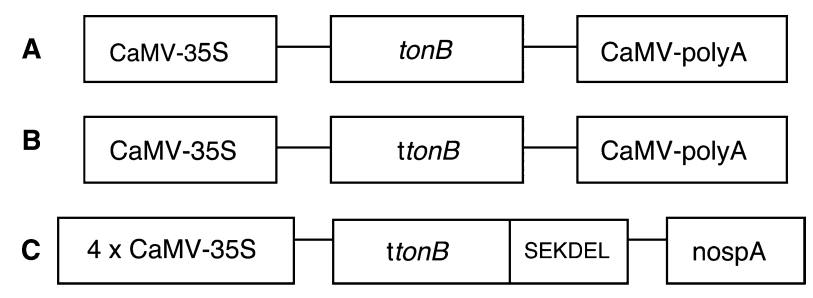

Figure 1 Plant expression cassettes containing either the full-length $(A)$ or truncated ton $B$ gene $(B \& C)$ lacking the codons for the $\mathrm{N}$-terminal transmembrane helix. Expression was controlled by either a single cauliflower mosaic virus 355 promoter (A \& B) or four 355 enhancers fused in tandem to the minimal 355 promoter $(C)$. In construct $C$, the tonB gene was cloned in frame with the SEKDEL ER retention signal sequence at the $\mathrm{C}$ terminus.

of $35 \mathrm{~S}$ promoter (primers $\mathrm{C} \& \mathrm{~B}$ ); (C) and the truncated TonB with a $\mathrm{C}$-terminal ER retention signal under control of $4 \times 35 \mathrm{~S}$ promoter (primers D $\& \mathrm{E}$ ). The first two constructs were assembled in the pGreen vector (http:// www.pgreen.ac.uk; Ref. 24) using the Xba I and $\mathrm{BamH}$ I endonuclease restriction sites (pGreen/tton $B$ and pGreen/ton $B$ ), and the third was assembled in the pPCV742 vector (kindly provided by Prof. Olof Olsson, Göteborg University, Sweden) using the BamH I restriction site (pPCV742/ttonB). The PCR products were purified with the QIAquick PCR Purification Kit (Qiagen, Hilden, Germany) and subjected to ligation into the respective vectors. The vectors produced were verified by DNA sequencing (ABI PRISM 3100 Genetic Analy2 ser; Applied Biosystems).

\section{Plant Growth and Transformation}

Arabidopsis thaliana plants of ecotype Columbia-0 (Col0 ) were used in all experiments. They were grown on fertilized soil/Perlite/Vermiculite mixture $(1: 1: 1)$ in a growth chamber with 16 - hour light $\left(22^{\circ} \mathrm{C}\right), 8$ - hour dark $\left(22^{\circ} \mathrm{C}\right)$ cycles at $70 \%$ humidity. The fluence rate of white light was $100 \mu \mathrm{mol}$ photons $/ \mathrm{m}^{2} / \mathrm{s}$ (PAR).

Transgenic plants were produced by a simplified Agrobacterium-mediated floral dip method of four-week-old Arabidopsis plants as described by Clough and Bent [25] and selected by germination on Murashige and Skoog (MS) medium containing $400 \mu \mathrm{g} / \mathrm{mL}$ cephotaxime (Sigma-Aldrich, Steinheim, Germany) and either $10 \mu \mathrm{g} / \mathrm{mL}$ glufosinate-ammonium (BASTA; Riedel-de Haën, Seelze, Germany) or $50 \mu \mathrm{g} / \mathrm{mL}$ kanamycin. Selection against BASTA was used for the plants transformed with the pGreen/tonB and pGreen/ttonB vectors. Selection against kanamycin was used for the plants transformed with the pPCV742/ttonB vector. Resistant plants were transferred to potting mix for analysis, self-pollination, and seed production. The seeds obtained from individual plants producing 100\% BASTA or kanamycin-resistant progeny were used for further experiments.

\section{Detection of Transgenic Inserts in the Plants}

The selected transformants were analyzed by PCR using the REDExtract-N-Amp ${ }^{\mathrm{TM}}$ Plant PCR Kit (Sigma-Aldrich) according to the manufacturer's protocol. Two different sets of primers were used for PCR. In each set, one primer was $35 \mathrm{~S}$ cassette-specific and another was tonB-specific.

\section{Production and Purification of the Recombinant TonB in E. coli}

Bacteria carrying pET28c/tonB plasmids [7] were grown on LB medium containing $50 \mu \mathrm{g} / \mathrm{mL}$ kanamycin (Sigma, Steinheim, Germany) at $37^{\circ} \mathrm{C}$ to an optical density (OD) of $0.8-1.0$ at $600 \mathrm{~nm}$. Isopropyl $\beta$-D-thiogalactoside (IPTG; Invitrogen, Groningen, The Netherlands) was added to a final concentration of $1 \mathrm{mmol} / \mathrm{L}$, and the culture was incubated for another 4 hours. Bacteria were harvested by centrifugation $(5000 \times \boldsymbol{g}$, $15 \mathrm{~min}$ ) and used for purification of the TonB protein. For protein expression, E. coli strain BL2l(DE3) pLysS (Novagen Inc., Madison, WI, USA) was used.

The frozen bacterial pellet was first subjected to X-PRESS (AB BIOX, Göteborg, Sweden) with subsequent resuspension in $50 \mathrm{mmol} / \mathrm{L}$ sodium phosphate buffer, $\mathrm{pH}$ 8.0, $300 \mathrm{mmol} / \mathrm{L} \mathrm{NaCl}, 1 \mathrm{mmol} / \mathrm{L}$ phenylmethylsulfonyl fluoride (PMSF; Sigma-Aldrich). After sonication on ice $(35 \mathrm{~W}, 6 \times 30$ second) and ultracentrifugation $(45,000 \times$ $\boldsymbol{g}, 45$ minutes), two fractions were obtained: one soluble fraction and one insoluble fraction. The soluble fraction was subjected to purification by immobilized metal-ion affinity chromatography (IMAC) under native conditions using the His-Select nickel affinity gel (Sigma-Aldrich) according to the manufacturer's protocol. As equilibrium and wash buffer, we used $50 \mathrm{mmol} / \mathrm{L}$ sodium phosphate ( $\mathrm{pH} 8.0$ ) with $0.3 \mathrm{~mol} / \mathrm{L} \mathrm{NaCl}$. Elution was performed with the same buffer supplemented with imidazole, the concentration of which varied in $50 \mathrm{mmol} / \mathrm{L}$ steps from 50 to $250 \mathrm{mmol} / \mathrm{L}$. All elution fractions were analyzed using Coomassie Brilliant Blue staining of SDS-PAGE gels. The purest fractions were pooled and concentrated in an Amicon Ultra centrifugal filter device (MW cutoff 10 kDa; Millipore, Billerica, MA, USA). The imidazolecontaining buffer was substituted for $25 \mathrm{mmol} / \mathrm{L} \mathrm{M}$ sodium phosphate buffer ( $\mathrm{pH}$ 8.0) using this filter device.

The pellet from the ultracentrifugation was resuspended in $0.1 \mathrm{~mol} / \mathrm{L}$ sodium phosphate $(\mathrm{pH} 8.0)$ and $8 \mathrm{~mol} / \mathrm{L}$ urea and sonicated as described earlier. Insoluble material was removed by ultracentrifugation 
$(50,000 \times \boldsymbol{g}, 60$ minutes $)$. The supernatant from the second centrifugation was also subjected to IMAC purification but under denaturing conditions according to the manufacturer's recommendations. The affinity gel was equilibrated with $0.1 \mathrm{~mol} / \mathrm{L}$ sodium phosphate buffer ( $\mathrm{pH} 8.0$ ) containing $8 \mathrm{~mol} / \mathrm{L}$ urea. The wash buffer was of the same content but had a $\mathrm{pH}$ of 6.3. Elution of the denatured protein was performed with $0.1 \mathrm{~mol} / \mathrm{L}$ sodium phosphate buffer ( $\mathrm{pH} 4.5$ ) containing $8 \mathrm{~mol} / \mathrm{L}$ urea. After analysis of elution fractions by SDS-PAGE, the purest fractions were pooled and concentrated as described earlier. The urea-containing buffer was changed to $25 \mathrm{mmol} / \mathrm{L}$ sodium phosphate $(\mathrm{pH} \mathrm{8.0)}$.

Purity check and quantification of the final protein solutions were performed by SDS-PAGE electrophoresis (staining with Coomassie Brilliant Blue) and UV spectrophotometry (NanoVue; GE Healthcare, Uppsala, Sweden). The produced proteins were used as positive controls in immunoblots and as antigens for the production of anti-TonB. Before we had produced our own anti-TonB antibodies, the first immunoblots of recombinant TonB were analyzed using pooled serum samples from patients not suffering from any $H$. pyloriassociated disease.

\section{Immunoblotting of Plant Material}

To prepare protein samples for TonB analysis, Arabidopsis tissues were ground in $50 \mathrm{mmol} / \mathrm{L}$ Tris- $\mathrm{HCl}(\mathrm{pH} 7.5)$ containing $1 \mathrm{mmol} / \mathrm{L}$ PMSF. Protein extracts were separated by SDS-PAGE and blotted onto nitrocellulose membrane Hybond-C (GE Healthcare). The membrane was blocked with 3\% BSA (Sigma-Aldrich) in TBS $(0.02 \mathrm{~mol} / \mathrm{L}$ Tris-HCl, $0.15 \mathrm{~mol} / \mathrm{L} \mathrm{NaCl}, \mathrm{pH}$ 7.4) and probed with anti-TonB serum produced in rabbit against the recombinant tTonB protein (Davids Biotechnologie GmbH, Regensburg, Germany). The scheme of immunization of rabbits included six injections. On Day $0,60 \mu \mathrm{g}$ antigen was administered subcutaneously. On Days 14, 21, 35, 49, and 63, $30 \mu \mathrm{g}$ was given subcutaneously. Water-in-oil emulsion (TiterMax; CytRx Corp., Los Angeles, CA) was used as adjuvant. TonB protein detection was carried out using alkaline phosphatase (AP)-conjugated anti-rabbit IgG (Promega, Madison,

$3 \mathrm{WI}$, USA) and visualized with NBT and BCIP (Promega). The experimental procedures of immunoblotting are outlined in Lindh et al. [26].

\section{Extraction of Genomic DNA and Southern Blot Analysis}

Plant genomic DNA was isolated using the Maxwell 16 system (Promega) according to the manufacturer's recommendations. Purity check and quantification were carried out using agarose gel electrophoresis and UV spectrophotometry (NanoVue; GE Healthcare). After digestion with restriction enzymes lacking recognition sites in the tonB or ttonB-SEKDEL nucleotide sequences, fragmented DNA was separated on $1 \%$ agarose gel and transferred to Hybond N+ nylon membrane (GE Healthcare). The membranes were hybridized at $65^{\circ} \mathrm{C}$ using the whole ton $B$ gene, labeled with $\left[\alpha-{ }^{32} \mathrm{P}\right] \mathrm{dCTP}$, as a probe using the random primers DNA labeling system (Invitrogen).

\section{Immunoprecipitation of the Antigen}

Arabidopsis seedlings, grown for 2 weeks on agar MS medium, were subjected to extraction with $10 \mathrm{mmol} / \mathrm{L}$ sodium phosphate, $0.15 \mathrm{~mol} / \mathrm{L} \mathrm{NaCl} \mathrm{(pH} \mathrm{7.5).} \mathrm{Six}$ hundred micrograms of total plant protein were used for the precipitation of tTonB using the Pierce Direct immunoprecipitation kit (Rockford, IL, USA). Precipitation was performed according to the manufacturer's protocol. The anti-TonB antibodies used in the immunoprecipitation were first purified from rabbit anti-serum by affinity chromatography using CNBr-activated Sepharose 4B (http://wiki.rrc.uic.edu/wiki/RRCPRL:_Antibody_Purification_by_Affinity_Chromatography). The precipitated protein was examined by SDS-PAGE, and the obtained band was analyzed by matrix-assisted laser desorption ionization-time of flight mass spectrometry (MALDI-TOF MS) peptide mapping and sequence identification (Alphalyse A/S, Odense, Denmark).

\section{Results and discussion}

\section{Overexpression of TonB in E. coli and Antibody Production}

The full-length tonB gene (HP1341) was cloned using the pET28C expression system [7] giving rise to an $\mathrm{N}$-terminal His-tag in the expressed protein. Expression of the corresponding protein in E. coli and immunolabeling with anti-His antibodies and serum from H. pylori-infected patients (Fig. 2A) revealed a band of the same size, around $35 \mathrm{kDa}$. This band was excised from the Coomassie Brilliant Blue-stained SDS-PAGE gel and analyzed by MALDI-TOF MS. The analysis confirmed that the detected protein was TonB (not shown). Large-scale overexpression of TonB (from $2 \mathrm{~L}$ of bacterial culture) and purification by IMAC resulted in pure protein (Fig. 2B). Both native and denatured TonB preparations were used for antibody production in rabbits. 


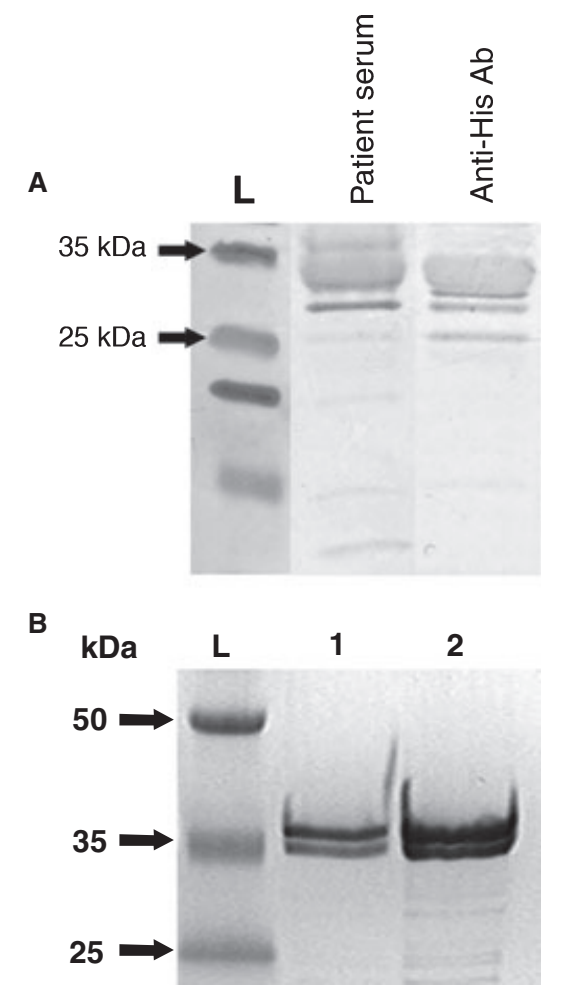

Figure 2 (A) Western blot analysis for recombinant TonB produced in E. coli using either an anti-His antibody or serum from H. pyloriinfected patients. $L$ stands for protein molecular mass standards; $(B)$ Coomassie Brilliant Blue-stained SDS-PAGE gel containing the recombinant TonB produced in E. coli and purified by native immobilized metal affinity chromatography (lanes 1 and 2; see Methods). L stands for protein molecular mass standards; Lanes 1 and 2 have 1 and $2.5 \mu \mathrm{g}$ of TonB loaded, respectively.

\section{PCR Amplification of the Full-Length and Truncated TonB, Construction of Plant Vectors, and Arabidopsis Transformation}

The PCR products of the full-length and the truncated ton $B$ showed the right size $(858$ and $756 \mathrm{bp}$, respectively) on ethidium bromide-stained agarose gels (Fig. 3). The identity of the amplified DNA was confirmed by DNA sequence analysis. We had introduced the desired restriction sites into the primers to facilitate cloning into the pGreen (Xba I and $B a m H$ I) and into the pPCV742 (BamH I) vectors. Each construct was confirmed for the presence and direction of the ton $B$ sequence by sequencing. The wild-type Arabidopsis plants of the Col-0 ecotype were successfully transformed using Agrobacterium carrying the different vectors. Twenty to forty transgenic plants for each construct were selected after initial seedling screening against either BASTA (for pGreen/tonB and pGreen/tton $B$ ) or kanamycin (pPCV742/ttonB). The selected plants were subjected to PCR screening for the presence

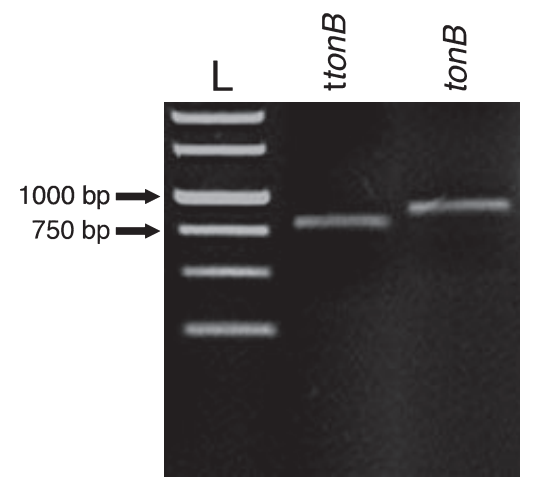

Figure 3 Agarose gel showing the unique PCR products of ton $B$ and tton $B$ genes obtained from the $\mathrm{pET} 28 \mathrm{c} /$ ton $B$ vector using the primers shown in Table 1. The labeling is as follows: (L) DNA molecular mass standards; (ttonB) the truncated tonB amplified with primers B \& $C$; (tonB) the full-length ton $B$ amplified with primers $A \& B$.

of either ton $B$ or tton $B$ (results not shown). The PCRpositive plants were tested further for the presence of the recombinant protein.

\section{Testing the Antisera Using Plant Extracts and Accumulation of the Recombinant TonB in Arabidopsis}

The antisera were tested with plants expressing TonB. As seen in Fig. 4, both antisera (but not the presera), raised either against the native or against the denatured E. coli-produced TonB, recognized a protein of approximately $35 \mathrm{kDa}$ in two of three tested transgenic lines (lines 1 \& 3 in Fig. 4) but not in the wild-type Arabidopsis plants. Line 2 showed no TonB expression although

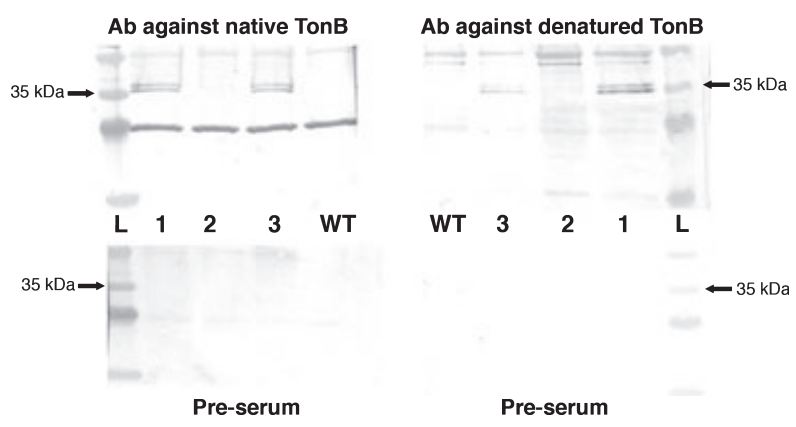

Figure 4 Analyses of the anti-TonB sera. Total protein extracts from plants were separated by SDS-PAGE, blotted onto nitrocellulose membranes and incubated with sera and presera raised against denatured and native recombinant TonB. (1), (2), and (3) stand for different transgenic Arabidopsis lines expressing tTonB. (WT) stands for wild-type Arabidopsis, and (L) for molecular mass standards. The secondary antibody was an alkaline phosphatase conjugate developed using NBT and BCIP. 


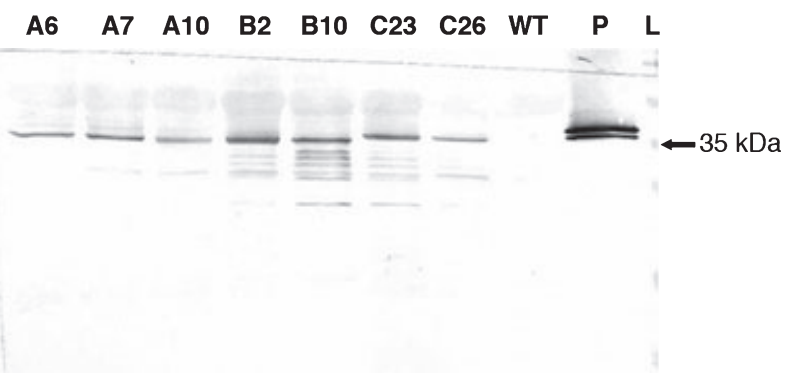

Figure 5 Immunoblot analysis of the occurrence of TonB in wild-type Arabidopsis plants (WT) and in transformants. The total protein extracts from plants $(80 \mu \mathrm{g})$ were separated by SDS-PAGE, blotted onto nitrocellulose membrane and immunolabeled with anti-TonB polyclonal antibodies (rabbit serum) and finally visualized using alkaline phosphatase-conjugated secondary antibody. A6, A7, and A10 denote Arabidopsis lines transformed with construct (A) (see Fig. 1); B2 and B10 denote Arabidopsis lines transformed with the construct (B); C23 and C26 denote Arabidopsis lines transformed with the construct $(C)$. $\mathrm{L}$ stands for molecular mass standards, WT for wild-type Arabidopsis (Col-0), and P for the positive control (recombinant TonB purified from E. coli).

the presence of the transgene had been confirmed with PCR (not shown). The reason for this would be either very low-level protein production (below the detection level of our method) or complete lack of synthesized TonB protein. This can be the result of either a positional effect of the inserted transgene, being introduced into a region of the plant DNA that is unfavorable for expression, or gene silencing as a result of co-suppression, a phenomenon frequently occurring in transgenic plants containing several copies of transgenes.

The antiserum against the native TonB detected a strong 25- $\mathrm{kDa}$ band in addition to the $35-\mathrm{kDa}$ TonB band. The $25-\mathrm{kDa}$ band appears in fractions from all tested plants, including the non-transformed negative wild-type control plants, which proves it is not of TonB origin but is the result of cross-reaction of the antinon-denatured TonB antibodies with intrinsic plant proteins. The serum raised against the denatured TonB detected fewer and weaker background proteins and was therefore the serum of choice for further experiments.

Western-blot detection of the constitutively expressed TonB in unfractionated leaf extracts from plants transformed with each of the three constructs is shown in Fig. 5. Comparison of the transgenic lines with non-transformed WT plants (as a negative control) reveals a specific band of a size that is of approximately the correct size when compared with the recombinant TonB protein expressed in E.coli (approximately $35 \mathrm{kDa})$. Immunoprecipitation using affinity purified anti-TonB antibodies revealed a thin band of the same size (Fig. 6A). MALDI-TOF peptide mass fingerprinting

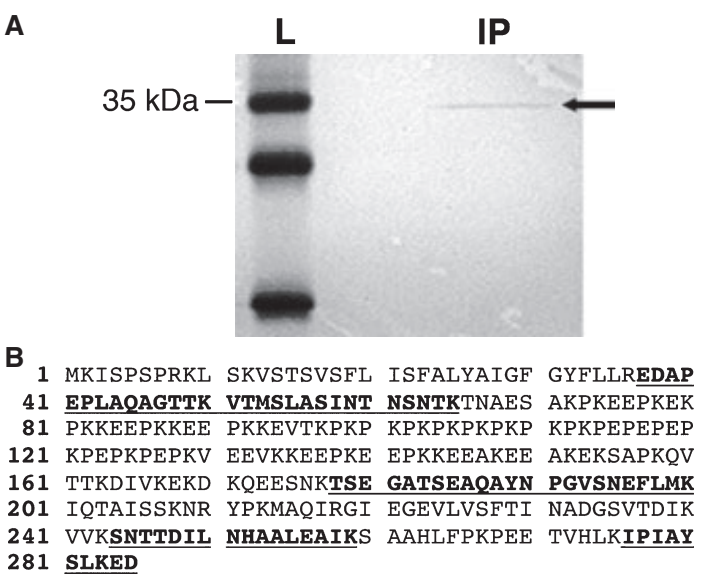

Figure $6(A)$ Immunoprecipitation of tTonB from transgenic plants. The arrow shows the tTonB band obtained; $(B)$ The results of MS analysis. Matching peptides are shown in bold and are underlined.

and MALDI-TOF/TOF peptide sequencing confirmed the precipitated protein to be TonB (Fig. 6B).

\section{The Number of Transgenes in Transformed Plants}

The number of transgenes inserted into the plant genome for each of the constructs was investigated by Southern blotting and varied between 1 and 4 in different lines. Fig. 7 shows the results for three transgenic lines representing each of the constructs (A, B, and C). Three different digests of each line (Xho I, Nde I, and BamH I) showed single bands that correspond to a transgene copy number of 1 .

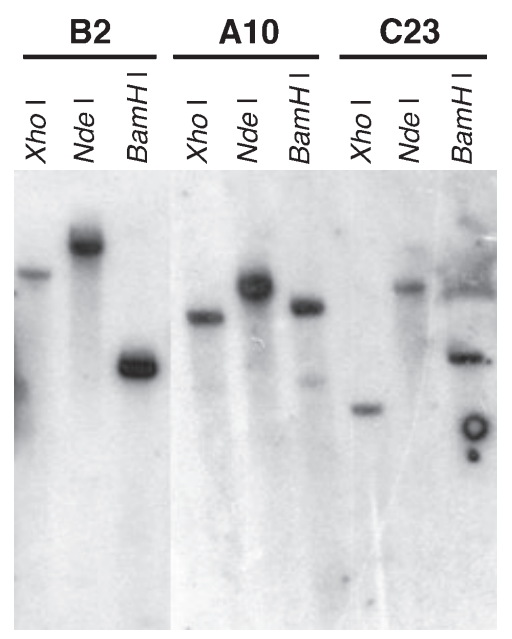

Figure 7 Southern blot analysis of three lines transformed with the different constructs $A$ (A10), B (B2), and C (C23) according to Fig. 1. Three different DNA digests of each line were produced using Xho I, $\mathrm{Nde}$ I, and BamH I restriction enzymes. 


\section{Comparison of the TonB Production in Plants Transformed with Different Constructs and Approximate Quantification of TonB Content}

To compare the TonB protein content in the plants transformed with the three different constructs, we chose the lines containing the same transgene copy number (lines A10, B2, and C23). In a semiquantitative analysis, the intensity of staining of bands after immunoblotting of equal amounts of $80 \mu \mathrm{g}$ total soluble protein from these transgenic lines (Fig. 5) showed only small differences between the constructs tested. However, plants carrying construct (b) (Fig. 1) are those with the highest amount of recombinant TonB. This can be explained by deletion of the transmembrane helix of the TonB protein and thereby as a result of increased protein solubility. To our surprise, we did not observe any increase in protein expression in plants carrying construct (c), leading to C-terminal SEKDEL ER retention signal, compared with construct (b) that lacks this sequence. An expression cassette containing four enhancer elements in tandem with the 35S promoter, as in construct (c), did not lead to increased TonB proteins levels either. Our examination showed that the effect of the stronger promoter and ER retention signal on transgene expression is probably transgene-specific and does not work in the case of TonB as opposed to the case with the HIV p24 gene [26]. Instead, ER accumulation most likely does not occur with TonB because of the lack of ER-directing sequences in the coding region.

For quantification of the TonB protein content in the transgenic Arabidopsis, we chose the line Al0, which had a single copy of the transgene and also displayed the lowest protein content among the investigated constructs. Different amounts of total soluble protein (TSP) $(20,40$, and $80 \mu \mathrm{g})$ from line Al0 were subjected to immunoblotting along with specific amounts of the purified recombinant tTonB protein $(60,20,10$, and $5 \mathrm{ng}$ ) produced in E. coli. The approximate content of TonB in the line Al0 was estimated by comparison of the staining intensity of the protein bands. The comparison showed a TonB content of approximately $250 \mu \mathrm{g} / \mathrm{g}$ TSP (not shown).

The objective of this study was to express one of the most dominant Helicobacter-specific antigens (TonB or HP1341) in the model plant Arabidopsis thaliana for further experiments leading to an oral vaccine antigen candidate. The corresponding gene was successfully transferred into Arabidopsis thaliana genome, and the protein was expressed from all three of our constructs. The absence of the $\mathrm{N}$-terminal transmembrane helix of TonB did not affect the production of the recombinant protein in Arabidopsis to any significant extent. Our suspicion that the presence of this transmembrane helix could inhibit accumulation of TonB in plants was not substantiated. The stronger promoter and fusion of the ER retention signal to the $\mathrm{N}$-terminal of the protein sequence did not lead to significant enhancement of TonB protein expression (construct c). At the same time, more accurate measurement of the amount of the expressed protein needs to be taken, and more transgenic lines have to be examined.

As was demonstrated for the HIV p24 protein produced in plants [27], A. thaliana is eaten raw by mice and therefore is suitable as a model system for edible vaccines in preclinical trials. Animal experiments with transgenic TonB-expressing Arabidopsis plants administrated orally are now on the way. A positive outcome of such studies, displaying immunogenicity and protection in mouse models, would pave the way for human preclinical studies using our TonB-carrying A. thaliana as an edible vaccine vector. Other more common food plants such as carrot would also be feasible as transgenic host [26] for a Helicobacter vaccine candidate consumed by humans. For large-scale production of TonB antigen as a pharmaceutical raw material, transformation of the chloroplast genome, rather than nuclear transformation, would be more suitable because such a technique routinely leads to higher levels of recombinant protein in plants [28].

\section{Acknowledgements and Disclosures}

This work was supported by grants to Ås from the Sparbanksstiftelsen Nya foundation and the Örebro University's Faculty for Medicine, Science and Technology. SA thanks the Nyckelfonden foundation, Örebro County Council, and the Swedish International Development Agency's Department of Research Cooperation for financial support. We also thank master students C. Mattsson, K. Broddegård, T. Santesson, and J. Brauer for their contribution to cloning of ton $B$ genes and characterization of transgenic Arabidopsis plants. Competing of interest: We declare that no competing interests exist. Irina Kalbina and Åke Strid are employees of Örebro University, and Sören Andersson and Lars Engstrand are employees of the Swedish Institute for Infectious Disease Control, both organizations being governmental authorities. Neither author has received any support or has any connections with organizations or companies with particular interest in the field of this study. Neither of us own stocks or patents related to the subject of this paper.

\section{References}

1 Vyas SP, Sihorkar V. Exploring novel vaccines against Helicobacter pylori: protective and therapeutic immunization. J Clin Pharm Ther 1999;24:259-72.

2 Hessey SJ, Spenser J, Wyatt JI, Sobala G, Rathbone BJ, Axon /surname> AT, Dixon MF. Bacterial adhesion and 
disease activity in Helicobacter associated chronic gastritis. Gut 1990;31:134-8.

3 Michetti P. Vaccine against Helicobacter pylori: fact or fiction? Gut 1997;41:728-30.

4 Boyanova L, Mitov I. Geographic map and evolution of primary Helicobacter pylori resistance to antibacterial agents. Expert Rev Anti Infect Ther 2010;8:59-70.

5 Graham DY, Fischbach L. Helicobacter pylori treatment in the era of increasing antibiotic resistance. Gut 2010; ????, ????-???? in

4 press. doi:10.1136/gut.2009.192757

6 Svennerholm AM, Lundgren A. Progress in vaccine development against Helicobacter pylori. FEMS Immunol Med Microbiol 2007;50:146-56.

7 Meinke A, Storm M, Henics T, et al. Composition of the ANTIGENome of Helicobacter pylori defined by human serum antibodies. Vaccine 2009;27:3251-9.

8 Schauer K, Gouret B, Carrière M, Labigne A, De Reuse H. Novel nickel transport mechanism across the bacterial outer membrane by the TonB/ExbB/ExbD machinery. Mol Microbiol 2007;63:1054-68.

9 Schauer K, Rodionov DA, De Reuse H. New substrate for TonB-dependent transport: do we only see the 'tip of the iceberg'? Trends Biochem Sci 2008;7:330-8.

10 Shultis DD, Purdy MD, Banchs CN, Wiener MC. Outer membrane active transport: structure of the BtuB: TonB complex. Science 2006;312:1396-9.

11 Iijima H, Takashi I, Kiyono H. Mucosal immune network in the gut for the control of infectious diseases. Rev Med Virol 2001;11:117-33.

12 Kong Q, Richter L, Yang YF, Arntzen CJ, Mason HS, Thanavala Y. Oral immunization with hepatitis B surface antigen expressed in transgenic plants. Proc Natl Acad Sci USA 2001;98:11539-44.

13 Wu Y-Z, Li J-T, Mou Z-R, Fei L, Ni B, Geng M, Jia Z-C, Zhou W, Zou L-Y, Tang Y. Oral immunization with rotavirus VP7 expressed in transgenic potatoes induced high titers of mucosal neutralizing IgA. Virol 2003;313:337-42.

14 Alvarez L, Pinyerd H, Crisantes J, Rigano M, Pinkhasov J, Walmsley A, Mason HS, Cardineau GA. Plant-made subunit vaccine against pneumonic and bubonic plague is orally immunogenic in mice. Vaccine 2006;24:2477-90.

15 Mason HS, Haq TA, Clements JD, Arntzen CJ. Edible vaccine protects mice against Escherichia coli heat-labile enterotixin (LT): potatoes expressing a synthetic LT-B gene. Vaccine 1998;16:1336-43.

16 Tacket CO, Mason HS, Losonsky G, Clements JD, Levine MM, Arntzen CJ. Immunogenecity in humans of a recombinant bacterial antigen delivered in a transgenic potato. Nature Med 1998;4:607-9.
17 Arakawa T, Chong DK, Langridge WH. Efficacy of a food plantbased oral cholera toxin B subunit vaccine. Nature Biotechnol 1998;16:292-7.

18 Arakawa T, Yu J, Langridge WH. Food plant-derived cholera toxin B subunit for vaccination and immunotolerization. $A d v$ Exp Med Biol 1999;464:161-78.

19 Mason HS, Ball JM, Shi JJ, Jiang X, Esters MK, Arntzen CJ. Expression of Norwalk virus capsid protein in transgenic tobacco and potato and its oral immunogenicity in mice. Proc Natl Acad Sci USA 1999;93:5335-40.

20 Tacket CO, Mason HS, Losonsky G, Esters MK, Levine MM, Arntzen CJ. Human immune responses to a novel Norwalk virus vaccine delivered in transgenic potatoes. J Infect Dis 2000;182:302-5.

21 Thanavala Y, Mahoney M, Pal S, Scott A, Richter L, Natarajan $\mathrm{N}$, Goodwin P, Arntzen CJ, Mason HS. Immunogenecity in humans of an edible vaccine for hepatitis B. Proc Natl Acad Sci USA 2004;22:4385-9.

22 Schouten A, Roosien J, van Engelen FA, et al. The C-terminal KDEL sequence increases the expression level of a single-chain antibody designed to be targeted to both the cytosol and the secretory pathway in transgenic tobacco. Plant Mol Biol 1996;30:781-93.

23 Wandelt CI, Khan MRI, Craig S, Schroeder HE, Spencer D, Higgins TJV. Vicilin with carboxyl-terminal KDEL is retained in the endoplasmic reticulum and accumulates to high levels in the leaves of transgenic plants. Plant J 1992;2:181-92.

24 Hellens RP, Edwards EA, Leyland NR, Bean S, Mullineaux PM. pGreen: a versatile and flexible binary Ti vector for Agrobacterium-mediated plant transformation. Plant Mol Biol 2000;42:819-32.

25 Clough SJ, Bent AF. Floral dip: a simplified method for Agrobacterium-mediated transformation of Arabidopsis thaliana. Plant $J$ 1995; 16:735-43.

26 Lind I, Wallin A, Kalbina I, Sävenstrand H, Engström P, Andersson S, Strid $\AA$. Production of the p24 capsid protein from HIV-1 subtype C in Arabidopsis thaliana and Daucus carota using an endoplasmic reticulum-directing SEKDEL sequence in protein expression constructs. Protein Expr Purif 2009;66:46-51.

27 Lindh I, Kalbina I, Thulin S, Scherbak N, Sävenstrand H, Bråve A, Hinkula J, Strid A, Andersson S. Feeding of mice with Arabidopsis thaliana expressing the HIV-1 subtype C p24 antigen gives rise to systemic immune responses. APMIS 2008; 116:985-94.

28 Daniell H, Kumar S, Dufourmantel N. Breakthrough in chloroplast genetic engineering of agronomically important crops. Trends Biotechnol 2005;23:238-45. 


\section{Author Query Form}

Journal: HEL

Article: $\quad 786$

Dear Author,

During the copy-editing of your paper, the following queries arose. Please respond to these by marking up your proofs with the necessary changes/additions. Please write your answers on the query sheet if there is insufficient space on the page proofs. Please write clearly and follow the conventions shown on the attached corrections sheet. If returning the proof by fax do not write too close to the paper's edge. Please remember that illegible mark-ups may delay publication.

Many thanks for your assistance.

\begin{tabular}{|l|l|l|}
\hline Query reference & Query & Remarks \\
\hline 1 & $\begin{array}{l}\text { AUTHOR: To facilitate sequential numbering, reference numbers have } \\
\text { been reordered. Please check. }\end{array}$ & \\
\hline 2 & $\begin{array}{l}\text { AUTHOR: Please give address information for Applied Biosystems: } \\
\text { town, state (if applicable), and country. }\end{array}$ & \\
\hline 3 & AUTHOR: Please expand NBT and BCIP. & $\begin{array}{l}\text { AUTHOR: If this reference has now been published in print, please add } \\
\text { relevant volume/page information. }\end{array}$ \\
\hline 4 &
\end{tabular}




\section{Please correct and return this set}

Please use the proof correction marks shown below for all alterations and corrections. If you wish to return your proof by fax you should ensure that all amendments are written clearly in dark ink and are made well within the page margins.

\begin{tabular}{|c|c|c|}
\hline Instruction to printer & Textual mark & Marginal mark \\
\hline Leave unchanged & ... under matter to remain & ( ) \\
\hline $\begin{array}{l}\text { Insert in text the matter } \\
\text { indicated in the margin }\end{array}$ & $h$ & $\begin{array}{l}\text { New matter followed by } \\
h \text { or } h \otimes\end{array}$ \\
\hline Delete & $\begin{array}{l}\text { I through single character, rule or underline } \\
\text { or }\end{array}$ & $\sigma$ or $\sigma(x)$ \\
\hline $\begin{array}{l}\text { Substitute character or } \\
\text { substitute part of one or } \\
\text { more word(s) }\end{array}$ & I through letter or & $\begin{array}{l}\text { new character / or } \\
\text { new characters / }\end{array}$ \\
\hline Change to italics & — under matter to be changed & $\leftarrow$ \\
\hline Change to capitals & $\equiv$ under matter to be changed & $\equiv$ \\
\hline Change to small capitals & $=$ under matter to be changed & $=$ \\
\hline Change to bold type & $\sim$ under matter to be changed & $\sim$ \\
\hline Change to bold italic & $\bar{\sim}$ under matter to be changed & $\underline{s i n}$ \\
\hline Change to lower case & Encircle matter to be changed & $\Rightarrow$ \\
\hline Change italic to upright type & (As above) & \\
\hline Change bold to non-bold type & (As above) & \\
\hline Insert 'superior' character & $\begin{array}{l}/ \text { through character or } \\
K \text { where required }\end{array}$ & $\begin{array}{l}y^{\prime} \text { or } y \\
\text { under character } \\
\text { e.g. } y^{2} \text { or } y^{2}\end{array}$ \\
\hline Insert 'inferior' character & (As above) & $\begin{array}{l}\lambda \\
\text { over character } \\
\text { e.g. } \hat{\Sigma}\end{array}$ \\
\hline Insert full stop & (As above) & $\odot$ \\
\hline Insert comma & (As above) & , \\
\hline Insert single quotation marks & (As above) & $\begin{array}{l}\dot{y} \text { or } \dot{x} \text { and/or } \\
\dot{y} \text { or } \dot{y}\end{array}$ \\
\hline Insert double quotation marks & (As above) & $\begin{array}{l}\ddot{y} \text { or } \ddot{y} \text { and/or } \\
\ddot{y} \text { or } \ddot{y}\end{array}$ \\
\hline Insert hyphen & (As above) & 1 \\
\hline Start new paragraph & 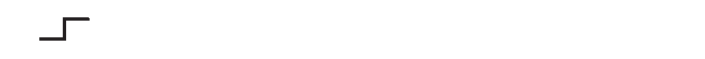 & 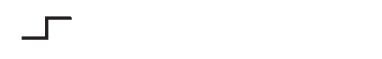 \\
\hline No new paragraph & $\infty$ & $\omega$ \\
\hline Transpose & $\sqcup$ & $\sqcup$ \\
\hline Close up & linking $\bigcirc$ characters & \\
\hline $\begin{array}{l}\text { Insert or substitute space } \\
\text { between characters or words }\end{array}$ & $\begin{array}{l}\text { I through character or } \\
\Lambda \text { where required }\end{array}$ & \\
\hline $\begin{array}{l}\text { Reduce space between } \\
\text { characters or words }\end{array}$ & $\begin{array}{l}\text { between characters or } \\
\text { words affected }\end{array}$ & $\uparrow$ \\
\hline
\end{tabular}

